\title{
(c) (1) \\ MATRIZES NEGRO-AFRICANAS DO CÁLCULO ALGÉBRICO: O CONHECIMENTO MATEMÁTICO PRESENTE NO PAPIRO
}

\author{
AHMES
}

Gustavo Henrique Araújo Forde ${ }^{1}$

Introdução: Este artigo resulta de trabalho de pesquisa cujo objetivo foi investigar matrizes matemáticas de ascendência africana e tecer reflexões que problematizem a presença africana no ensino de matemática, em particular, no ensino de cálculo algébrico. Por meio de procedimentos de análise histórica, investigamos a presença egípcio-africana no desenvolvimento do pensamento matemático no período de aproximadamente 2000 a.C. até 332 a.C., época que corresponde ao período do surgimento, apogeu e declínio do Egito faraônico e à fase inicial do período Helênico.

Palavras-chave: Matemática africana. História da matemática. Álgebra egípcioafricana.

\section{AFRICAN-BLACK MATRICES OF ALGEBRAIC CALCULUS: THE MATHEMATICAL KNOWLEDGE PRESENT IN THE PAPYRUS AHMES}

Abstract: This article is the result of research work whose objective was to investigate mathematical matrices of African descent and to weave reflections that question the African presence in mathematics teaching, in particular in the teaching of algebraic calculus. Through historical analysis procedures, we investigated the Egyptian-African presence in the development of mathematical thinking from about $2000 \mathrm{BC}$ to $332 \mathrm{BC}$, which corresponds to the period of the rise, heyday, and decline of Pharaonic Egypt and the early phase of the Hellenic period.

Keywords: African mathematics. Mathematics history. Egyptian african algebra.

\footnotetext{
${ }^{1}$ Doutor em Educação e professor adjunto do Centro de Educação da Universidade Federal do Espírito Santo (Ufes), onde atua na área Educação das Relações Étnico-Raciais. É pesquisador do Núcleo Capixaba de Pesquisa em História da Educação (NUCAPHE - Ufes e, do Núcleo de Estudos AfroBrasileiros (NEAB - Ufes). Desenvolve estudos e pesquisas em afrodescendência e relações étnicoraciais na educação, com interesse especial nos campos da história da educação da população negra, do movimento negro e da matemática. Atualmente é Pró-Reitor de Assuntos Estudantis e Cidadania da Ufes.
} 


\section{MATRICES AFRO-NEGRAS DE CÁLCULO ALGEBRAICO: EL CONOCIMIENTO MATEMÁTICO PRESENTE EN EL PAPIRO AHMES}

Resumen: Este artículo es el resultado de un trabajo de investigación cuyo objetivo era investigar matrices matemáticas de ascendencia africana y tejer reflexiones que cuestionen la presencia africana en la enseñanza de las matemáticas, en particular en la enseñanza del cálculo algebraico. A través de procedimientos de análisis histórico, investigamos la presencia egipcio-africana en el desarrollo del pensamiento matemático desde aproximadamente el 2000 a. C. hasta el 332 a. C., que corresponde al período de ascenso, apogeo y declive del Egipto faraónico y la primera fase del período helénico. .

Palabras clave: matemática africana. Historia de la matemática. Álgebra africana egipcia.

\section{MATRICES DE CALCUL ALGEBRIQUE NOIRES AFRICAINES: LES CONNAISSANCES MATHEMATIQUES PRESENTES DANS LE PAPYRUS AHMES}

Résumé: Cet article est le résultat de travaux de recherche dont l'objectif était d'étudier des matrices mathématiques d'ascendance africaine et de tisser des réflexions interrogeant la présence africaine dans l'enseignement des mathématiques, en particulier dans l'enseignement du calcul algébrique. À travers des procédures d'analyse historique, nous avons étudié la présence égypto-africaine dans le développement de la pensée mathématique d'environ 2000 à 332 av..

Mots-clés: mathématiques africaines. Histoire des mathématiques. Algèbre africaine égyptienne.

\section{MATRIZES NEGRO-AFRICANAS DO CÁLCULO ALGÉBRICO: O CONHECIMENTO MATEMÁTICO PRESENTE NO PAPIRO AHMES}

Este artigo resulta de trabalho de pesquisa cujo objetivo foi investigar matrizes matemáticas de ascendência africana e tecer reflexões que problematizem a presença africana no ensino de matemática, em particular, no ensino de cálculo algébrico. Por meio de procedimentos de análise histórica, investigamos a presença egípcio-africana no desenvolvimento do pensamento matemático no período de aproximadamente 2000 a.C. até 332 a.C., época que corresponde ao período do surgimento, apogeu e declínio do Egito faraônico e à fase inicial do período Helênico. 
Alvo de muita admiração e mistérios, a civilização egípcia foi - e ainda é - alvo de distorções científicas. Distorções com relações estreitas com aspectos da história da matemática, tal como a tentativa de deslocar o Egito da África para o Oriente Médio, uma prática universalmente repetida acriticamente nas mais consagradas obras de referência em história da matemática publicadas no Brasil. Corrigir essa distorção, a partir dos aportes oferecidos pela ciência, foi uma das contribuições que Cheikh Anta Diop $^{2}$ deixou para aqueles interessados no reexame da história da África.

O Egito é um país negro, com uma civilização criada por negros, qualquer tese que tentasse provar o contrário careceria de futuro. Os protagonistas de tais teorias não desconheciam este fato. Assim, seria mais seguro e mais sábio destituir o Egito, simplesmente e muito discretamente, de todas as suas criações, em favor de uma nação realmente branca (a Grécia). Esta atribuição falsa à Grécia dos valores de um Egito chamado branco revela uma profunda contradição, que não é a menos importante prova da origem negra do Egito (DIOP apud NASCIMENTO, 1996, p. 46).

O Egito, apesar de localizado geograficamente no continente africano, continua sendo "apresentado" em muitas obras acadêmicas e didáticas a partir do contexto histórico e cultural do Oriente Médio, ou, como pertencente a uma suposta África branca. Entretanto, a despeito das discrepâncias apresentadas, hoje, pode-se afirmar que "a base da população egípcia no período pré-dinástico era negra".

Nos manuais de maior divulgação, entretanto, a questão é suprimida: na maioria dos casos, afirma-se simples e claramente que os egípcios eram brancos, e o leigo fica com a impressão de que uma afirmação desse tipo deve necessariamente ter como base uma sólida pesquisa anterior. Mas, conforme se mostrou neste capítulo, essa pesquisa não existe. E, assim, gerações após gerações foram enganadas. Muitas autoridades no assunto contornam a dificuldade falando em brancos de pele vermelha e brancos de pele negra, sem que por isso se abale o senso de lógica (DIOP, 1983, p. 42).

A conclusão de Diop resulta de uma série de evidências históricas, provas científicas, e dados produzidos a partir de: 1) Teste de dosagem de melanina; 2)

\footnotetext{
${ }^{2}$ Considerado a personalidade científica africana que mais marcou o século XX, a quem é atribuído o pioneirismo no desenvolvimento de pesquisas historiográficas africanas numa perspectiva descolonizada, detendo também os créditos de descontruir as teorias racistas que afirmavam ser o povo egípcio branco ou vermelho claro.
} 
Medidas osteológicas; 3) Grupos sanguíneos, 4) Testemunhos da Bíblia, 5) Fontes arqueológicas, 6) A classificação dos egípcios pelos autores clássicos da antiguidade etc. Para citar alguns exemplos, com base em monumentos e objetos arqueológicos da época dinástica, Diop demonstra as feições tipicamente negróides dos faraós Narmer (I dinastia), Zoser (III dinastia), Quéops (XI dinastia), Sesóstris I, a rainha Amósis Nefertári, e Amenófis I. Corroborando com esta assertiva, o cientista Volney viajando pelo Egito entre 1783 e 1785, em plena escravidão negra, tece a mesma constatação sobre os coptas (população que originou os faraós):

Todos eles têm faces balofas, olhos inchados e lábios grossos, em uma palavra, rostos realmente mulatos. Fiquei tentado a atribuir essas características ao clima, até que, visitando a Esfinge e olhando para ela, percebi a pista para a solução do enigma. Completando essa cabeça, cujos traços são todos caracteristicamente negros [...] (VPLNEY apud DIOP, 1983, p. 55).

O Egito faraônico foi uma civilização africana erigida por um povo negro, de lábios grossos, cabelos crespos e pernas finas; e, compartilha vários aspectos culturais com diversos países africanos. Diop (1983) destaca a circuncisão, que, segundo o autor, para Heródoto seria de origem africana e constatada em múmias datadas de 4000 a.C. e, Nascimento (1980) ressalta um aspecto cultural que interessa particularmente aos afrobrasileiros:

[...] aquele onde Diop menciona as relações do antigo Egito com a África negra [sic], de modo específico com os iorubás. Parece que tais relações foram tão íntimas a ponto de se poder 'considerar como um fato histórico a possessão conjunta do mesmo habitat primitivo pelos iorubás e egípcios'. Diop levanta a hipótese de que a latinização de Horus, filhos de Osíris e Ísis, resultou no apelativo Orixá. Seguindo essa pista de estudo comparativo, ao nível da linguística e outras disciplinas, Diop cita J. Olumide Lucas em The religion of the Yorubas, o qual traça os laços egípcios do seu povo iorubá, concluindo que tudo leva à verificação do seguinte: a) uma similaridade ou identidade de linguagem; b) uma similaridade ou identidade de crenças religiosas; c) uma similaridade ou identidade de ideias e práticas religiosas; d) uma sobrevivência de costumes, lugares, nomes de pessoas, objetos, práticas, e assim por diante (NASCIMENTO, 1980, p. 252)

Reinserir o Egito no contexto histórico-cultural africano e toda a sua inventividade matemática à memória dos afro-brasileiros, além de uma necessidade 
histórica, contribuirá para a compreensão de que, em grande medida, aquilo que a Lei 10.639/03 propõe incluir, de certa forma já permeia o cotidiano do ensino da matemática escolar, uma vez que, o Egito, além de transmitir valiosas contribuições às civilizações da antiguidade, também deixou um importante legado científico e cultural à era moderna; tais conhecimentos foram transmitidos pelo mundo greco-romano ao mundo árabe e espalhados na civilização ocidental. De outro modo, Diop nos ensina que "a antiguidade egípcia é, para a cultura africana, o que é a Antiguidade greco-romana para a cultura ocidental; a construção de um corpus de ciências humanas africanas deve ter isso como base" (DIOP, 1983, p. 68).

Diversos são os artefatos e mentefatos egípcios legados à humanidade, aqui, neste artigo, interessam-nos aqueles que enunciam a matriz africana no desenvolvimento do pensamento matemático ocidental. É sabido que a matemática ocidental não se refere essencialmente aos conhecimentos de matrizes greco-romanas, mas resulta de trocas, disputas e conflitos entre os diversos povos da antiguidade, haja vista que, no mediterrâneo antigo, os povos não estiveram incomunicáveis ou "blindados" às culturas estrangeiras, muito menos aprisionados no interior de sua "própria" cultura.

Diante do conjunto de evidências e registros históricos que dispomos na atualidade, não há razões para subestimar a presença de matrizes africanas no pensamento matemático, ou seja, a busca da genealogia da matemática ocidental exclusivamente na Grécia, só é possível fora do terreno da história. Negar ou omitir a presença negro-africano é corroborar com um projeto segregacionista com dimensões e impactos planetários, cujo eurocentrismo tem sido responsável por extirpar as matrizes africanas e de reificar o modelo cultural Europeu.

O fato é que, ainda nos dias atuais, a ideia de um Egito negro-africano apresenta desconforto para muitos historiadores matemáticos. Senão, como explicar os esforços teórico-metodológicos de situá-lo no contexto do Oriente Médio, distorcendo seu pertencimento histórico-cultural negro-africano. Há de se destacar que o desenvolvimento dos conhecimentos que hoje nomeamos de matemáticos é quase tão antigo quanto a espécie humana. $\mathrm{O}$ testemunho matemático mais antigo, conhecido por nós, é o “osso Ishango, com mais de 8000 anos de idade, encontrado em Ishango, às 
margens do lago Edward, no Zaire ${ }^{3}$, mostrando números preservados por meio de entalhes no osso" (Eves, 2004, p. 26); este testemunho nos faz pensar que encontraremos em África o berço das mais antigas experiências matemáticas.

Entre a matemática ossificada no Bastão de Ishango (8.000 a.C.) e a matemática dedutiva atribuída a Tales de Mileto (600 a.C.), houve uma infinidade de avanços e descobertas matemáticas desenvolvidas pelos quatro cantos do planeta. É neste intervalo espaço-temporal - entre Ishango e Tales - que encontraremos registros matemáticos das civilizações que se desenvolveram a partir de 3.000 a.C., ao longo dos rios Nilo, na África, dos rios Tigre e Eufrates, no Oriente Médio (Mesopotâmia), e do rio Amarelo, na China. Destes, aqui, dediquei-me investigar o Egito antigo. Sobre o Bastão de Ishango, de acordo com Dirk Huylebrouck (2006), pesquisadores suspeitam que:

[...] o bastão de Ishango seria um simples testemunho de um procedimento de contagem numa comunidade em que as bases 10 e 6 (ou 3 e 4) eram sempre misturadas e utilizadas juntas. Isso explica por que as somas das colunas são 60 e 48 - dois números múltiplos de 3 e de 4 . Com sistemas de bases 10 e 8 , teríamos pelas mesmas razões, 80 e 40 (Huylebrouck, 2006, p. 45-46).

\section{Figura 1 - Detalhe do bastão e representação estilizada dos entalhes}

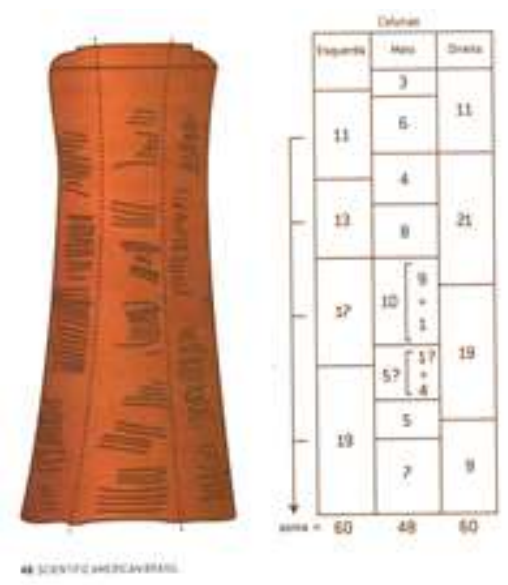

Fonte: Huylebrouck (2006).

É sabido que os primeiros avanços das formas de saberes e fazeres matemáticos - na perspectiva ocidental do termo - coexistiram com o advento da agricultura, da

\footnotetext{
${ }^{3}$ Atualmente República Democrática do Congo.
} 
metalurgia, da tecelagem e do comércio, ainda no período neolítico. Enquanto os primeiros exigiam um tipo de linguagem marcadamente concreta, este último - o comércio - provavelmente exigiu uma linguagem fortemente abstrata e um pouco desvinculada da empiria. Ambos, entretanto, empiria e abstração, são linguagens e racionalidades complementares, pois tanto na manufatura de tecidos, como na produção de cerâmicas, de cestos e na medição de terrenos agrícolas, a noção de espaço e de números pode nos revelar pensamentos abstratos em regime de complementariedade com pensamentos empíricos.

É evidente que, como produto de sua interação com o meio externo, a ciência matemática desenvolveu-se de diferentes formas, em distintas localidades do planeta, com uma característica comum, a de estarem sempre voltadas para as atividades cotidianas. Assim foi, nas antigas civilizações desenvolvidas às margens dos rios "Nilo, do Tigre, do Eufrates, do Indo, depois ao longo do Ganges, do Huang Ho e, enfim, do Yang-Tse" (Struik, 1997, p. 45). As matemáticas, ao lado de outras ciências, apresentavam, naquela época, ligações estreitas com as características agrossedentárias dessas sociedades, marcadas pelos sistemas de irrigação e pela agricultura. Para Struik (1997), estas foram algumas das condições que favoreceram o desenvolvimento, nessas civilizações, de um tipo de matemática aritmético-algébrica. Sobre a aritmética e a álgebra, o autor afirma que

[...] surgiram como uma ciência prática com o objetivo de facilitar o cálculo do calendário, a administração das colheitas, a organização das obras públicas e a cobrança de impostos. A ênfase inicial foi dada naturalmente à aritmética prática e à medição. Porém, uma ciência cultivada durante séculos como um ofício especial e cuja tarefa não é apenas aplicar, mas também ensinar os seus segredos, desenvolve tendências para a abstração. Gradualmente ela virá a ser estudada por si própria. A aritmética transformou-se em álgebra, não só porque possibilitava melhores cálculos práticos, mas também porque era o resultado natural de uma ciência cultivada e desenvolvida nas escolas dos escribas. Pelas mesmas razões, a medição deu origem aos começos - mas não mais do que isso - da geometria teórica (STRUIK, 1997, p. 48).

Apesar da escassez documental que nos forneça registros matemáticos do Egito antigo, algumas fontes estão disponíveis, conforme a seguinte descrição cronológica apresentada por Eves (2004): 
- 3100 a.C. - No museu de Oxford, encontra-se um cetro real egípcio dessa época. Nele, encontram-se gravados em hieróglifos egípcios alguns números da ordem de centenas de milhares e milhões.

- 2600 a.C. - Data aproximada da construção da grande pirâmide de Gizé, envolvendo alguns problemas de matemática e de engenharia. A pirâmide contém mais de 2.000.000 de blocos de pedras pesando em média 2,5 toneladas cada um, todos ajustados entre si.

- 1850 a.C. - Essa é a data provável do papiro Moscou (ou Golonishev), um texto matemático que contém 25 problemas matemáticos. O papiro, adquirido no Egito em 1893, agora se encontra no Museu de Belas-Artes de Moscou.

- 1850 a.C. Data dessa época o mais antigo instrumento astronômico existente, um misto de fio de prumo e colimador. Encontra-se preservado no Museu de Berlim.

- 1650 a.C. Data provável do papiro Ahmes (ou Rhind), um texto matemático na forma de manual prático que contém 85 problemas copiados de um trabalho mais antigo.

- 1500 a.C. Possível data de construção de um relógio de sol egípcio que se apresenta como o relógio de sol mais antigo que existe.

- 1200 a.C. - Conclusão da construção do Grande Vestíbulo do templo por Ramsés II; cujas colunas de setenta e oito pés de altura o tornam o maior vestíbulo colunar jamais construído pelo homem.

Dessas fontes, trabalhei com as informações disponibilizadas na literatura que tratam dos papiros Ahmes, uma fonte primária que oferece importantes informações sobre aspectos da matemática africana desenvolvida no antigo Egito. Nele, encontra-se problemas de aritmética, álgebra e geometria. O papiro Ahmes, também conhecido como papiro Rhind, é o documento histórico mais antigo da matemática, provavelmente escrito por volta de 1650 a.C., encontrado em 1858, no vale do Nilo. O nome de Ahmes, ${ }^{4}$ que lhe é atribuído por ser o nome do escriba que o copiou e, consta que este

\footnotetext{
${ }^{4}$ Segundo Struik (1997), Ahmes é o primeiro nome conhecido da história da matemática.
} 
papiro é cópia de um documento ainda mais antigo, que remonta à $12^{\mathrm{a}}$ Dinastia faraônica, durante o reinado de Amenemhat III, datado de 1850 e 1800 a.C.

O papiro Ahmes constitui dois rolos que, segundo Fontes (1969), medem, respectivamente, 206 e $319 \mathrm{~cm}$, totalizando 5 metros e $25 \mathrm{~cm}$ de comprimento por 33 $\mathrm{cm}$ de largura. Consta que ele foi produzido durante o reinado de Aquserré Apopis $(1850-1730$ a.C.).

O documento em questão tem, como conteúdo principal, questões relativas: à equivalência de frações; às operações com números fracionários; às proporções; às regras de três; à regra de falsa posição; à decomposição em partes proporcionais, além das demais, que se relacionam a outras questões aritméticas ou aos problemas geométricos. [...] (FONTES, 1969, p. 72).

Aqui, nos limitaremos, em função dos limites de um artigo desta natureza, a evidenciar aspectos documentados nos papiros egípcios que nos atestam a anterioridade qualificada $^{5}$ dos africanos no desenvolvimento desta ciência. Entretanto, que espécie de documento constitui o papiro Ahmes? Para Raja Gabaglia (1897a), há duas hipóteses distintas sobre o papiro Ahmes: uma considera-o um manual prático de matemática, hipótese grandemente aceita, e a outra sugere ser ele um caderno de aluno contendo exercícios dados numa "escola". Se reconhecermos o papiro Ahmes como caderno de aluno, podemos pressupor que os aspectos matemáticos ali registrados tal como a ponta de um iceberg, capaz de nos anunciar um conhecimento mais amplo e não ainda não conhecido.

O papiro Ahmes contém 14 problemas de natureza algébrica, cujos enunciados resultam em equações do $1^{\circ}$. grau a uma incógnita, por exemplo, aquele que diz "Qual a quantidade que somada à sua quarta parte é igual a 15?” (FONTES, 1969, p. 97. A este problema está associada a seguinte solução; "Toma-se o número 4, que somado à quarta parte, resulta 5. Sendo 5 a têrça parte de 15, 4 é um terço do número procurado, que é 12” (FONTES, 1969, p. 97).

Nesta fonte, há presença de inúmeros problemas lineares com uma incógnita, a qual era denominada de hau ou aha. Por essa razão, "a álgebra egípcia é, por isso,

\footnotetext{
${ }^{5}$ A anterioridade egípcia é fartamente reconhecida nas obras de história da matemática. O diferencial que trazemos é a necessidade de qualificá-la positivamente, como também, de atribuir-lhe pertencimento africano.
} 
denominada por vezes de "cálculo aha" (Struik, 1997, p. 55). Chamou-nos a atenção a anterioridade egípcia diante da resolução de alguns problemas, cujas formulações encontram similaridades naqueles presentes no ensino de matemática na atualidade, como o problema: "a soma de 2/3, 1/2 e 1/7 de uma quantidade com ela própria dá 33 . Qual é a quantidade? (Struik, 1997, p. 55)”. Tal problema, expresso na linguagem comum, pode ser expresso na linguagem matemática da maneira: $\frac{2}{3} x+\frac{1}{2} x+\frac{1}{7}+x=33$.

Neste sentido, o problema egípcio acima descrito parece-nos ainda aplicável ao ensino de matemática nos dias atuais. Poderíamos, por exemplo, apresentá-lo no plano de ensino para as séries finais do Ensino Fundamental II, de uma maneira renovada, como sugerimos a seguir:

- Elabore uma expressão algébrica correspondente à frase: A soma de 2/3, 1/2 e 1/7 de uma quantidade com ela própria dá 33. Em seguida, resolva-a, sendo a incógnita um número racional.

Há, ainda, na álgebra presente no papiro Ahmes, outros problemas de fácil reconhecimento nos currículos de matemática nos dias atuais, como

[...] do mais alto interesse, pois já nelles encontrão-se conhecimentos algébricos relativamente importantes, e sufficientes para arrancar a Diophantos a gloria que geralmente lhe era attribuida de $<<$ inventor da álgebra $>>$. Igualmente, esses problemas apresentam alguns signaes mathematicos, não sendo hoje, portanto, mais aceitável attribuir-se a Diophantos a prioridade no emprego dos symbolos algébricos (GABAGLIA, 1897b, p. 217).

Os egípcios chamavam de cálculo de $A h a$ ou Hau os cálculos que hoje correspondem à nossa equação do primeiro grau com uma incógnita. Hau ou há significava montão, acervo ou cúmulo. No papiro Ahmes, esses problemas, ainda de acordo com Gabaglia, dividem-se em duas categorias: uma se refere a números abstratos (problemas de n. 24 a 34) e outra se refere a uma medida egípcia, chamada bescha. Em ambos, a solução vinha acompanhada da prova, verificando a exatidão da resolução. 
Ahmes para resolver esses problemas segue marcha muito methodica, que pode ser explicada nas seguintes palavras: em primeiro logar, reduz a um só todos os termos que contem a incógnita, os quaes pelo enunciado já se acham separados da quantidade conhecida; a reducção effectua-se de dous modos ou escrevendo simplesmente um em seguida aos outros os termos primitivos, o que equivale a pôr em evidência a incógnita, ou reduzindo os termos fraccionarios a mesma denominação e depois sommando-os (GABAGLIA, 1897b, p. 218).

Vejamos alguns desses problemas presentes no papiro Ahmes.

- Problema n. 24: Hau, seo sétimo, elle mesmo faz: 19.

- Problema n. 26: Hau, seo quarto, elle mesmo dá: 15.

- Problema n. 34: Hau, seo meio, seo quarto, elle mesmo, isto dá: 10.

$\mathrm{Na}$ atualidade, esses problemas podem ser traduzidos por meio das seguintes equações literais:

- Problema n. 24: $\quad \frac{1}{7} x+x=19$.

- Problema n. 26: $\frac{1}{4} x+x=15$.

- Problema n. 34: $\quad \frac{1}{2} x+\frac{1}{4} x+x=10$.

Diante desses e outros problemas, Raja Gabaglia (1897b), já no século XIX, nos dizia:

[...] a analyse dos problemas do hau mostra naturalmente uma marcha algébrica. É fora de toda a discussão, que admira, ou antes assombra, encontrar processos tão adiantados em épocas tão remotas, os quaes deixam entrever nos centros scientificos do antiquisimo Egyto profundos conhecimentos mathematicos, de muito superiores aos que geralmente se lhes attribuiam e que diminuem de outro tanto as glorias dos gregos e dos hindus. Realmente, que extenso horisonte scientifico não se avista dos cálculos de Ahmes? (GABAGLIA, 1897b, p. 232-233) [grifo nosso].

Vale mencionar que os próprios gregos mencionam seus laços estreitos com os sábios africanos do antigo Egito. Segundo Gabaglia (1897a), "talvez Pythagoras tivesse adquirido o conceito do irracional no Egypto por onde viajou e cujos mathematicos já sabiam calcular um valor aproximado para $\pi ”$ (p. 144). A destituição da presença africana no ensino e na história da matemática, podemos dizer, coaduna-se com 
discursos forjados na construção de uma hegemonia cultural branco-européia. O próprio Gabaglia, no século XIX, já questionava isso, em face da tradição universal dos matemáticos modernos em encontrar em Diofanto ${ }^{6}$ os primórdios da álgebra, indicando a hibridização como marca dos processos de desenvolvimento da matemática ocidental:

Porque não recorrer a Diophantos, a Herão de Alexandria para nelles estudar o caracter dos processos de Ahmes, elles que se apresentam tão pouco hellenos, e são tão accentuadamente egypcios? (GABAGLIA, 1897b, p. 233).

Aqui, ocupamo-nos em problematizar a dualidade Ocidente vs Oriente introduzindo um novo sujeito histórico, a África e os negros-africanos, que constituem o corpus filosófico e científico do Egito antigo. Se, por necessidade, considerarmos o espaço de tempo que separa os cálculos egípcios dos helenos, veremos, como Gabaglia, que

É realmente espantoso o conhecimento mathematico do autor do papyro Rhind ${ }^{7}$, si attendermo a longínqua época da sua composição e si o compararmos com a sciencia dos mais antigos entre os gregos. Reflectindo-se que de Ahmes a Thales ha no mínimo um intervallo de dez séculos; considerando-se de um lado o relativamente muito que aquelle sabia, e do outro as descobertas elementares a este attribuidas pelo orgulho e vaidade nacionaes, fica-se sob um sentimento de admiração tão intenso, quanto o que apodera-se de todos os viajantes que vão até as grandes pyramides - os últimos limites dos tempos históricos -, e até a grande Sphinge cujos olhares de profundo pensamento se alongam indefinidamente sobre a planície illimitada, parecendo procurar nos arcanos do mais longínquo futuro as soluções dos problemas que vem tentando resolver desde as priscas eras do mais remoto passado. Maspero diante deste colosso prodigioso, que é a estatua mais antiga até hoje achada, reconheceu ser a arte que a concebeu e talhou uma arte completa, senhora de si, segura de seus effeitos; e perguntou: quantos séculos não lhe tinham sido necessários para chegar a tal grao de madureza e perfeição? Idêntica pergunta irrompe dos lábios de quem estudar os processos mathematicos do papyro Rhind: para escrever um trabalho semelhante, quantos séculos não foram precisos à sciencia!? (GABAGLIA, 1897c, p. 291) [grifo nosso].

Esses fatos, mais do que vestígios, constituem evidências de que "boa" matemática já era praticada por negros em África, que, por intermédio dos gregos, foi

\footnotetext{
${ }^{6}$ Diofanto de Alexandria teve uma importância enorme para o desenvolvimento da álgebra e uma grande influência sobre os europeus que posteriormente se dedicaram à teoria dos números (Eves, 2004, p. 207).

${ }^{7} \mathrm{O}$ papiro Ahmes, também é conhecido como papiro Rhind, encontrado em 1858, no vale do Nilo, pelo escocês A. Henry Rhind, o qual também lhe empresta o nome, junto ao nome de Ahmes, que lhe é atribuído por ser o nome do escriba que o copiou.
} 
levada para todo o ocidente. De que o ensino de matemática está constituído de saberes e fazeres africanos não há dúvidas! Não há dúvidas também, quanto à necessidade de problematizar o pertencimento étnico-cultural de tais conhecimentos, objetivando deslocar a civilização grega da posição de centralidade única ou universal do desenvolvimento matemático.

Outrora, perguntamos: causaria espanto demonstrar problemas matemáticos de larga aplicabilidade, contextualizando-os originariamente em um universo negroafricano datado de aproximadamente 4000 anos atrás? Em que medida o grau de espanto (se houver?), estaria implicado no fato em ter que reconhecer a provável autoria de um povo "negroide", nestes conhecimentos?

Se por um lado, as obras de história da matemática reconhecem a multiplicidade de matrizes no desenvolvimento do pensamento matemático, seu caráter plural, o dinamismo das descobertas e usos, a narrativa hegemônica da história da matemática ainda produz sentidos eurocentrados.

O significado do discurso histórico são estruturas ideológicas ou imaginárias; mas elas são afetadas por um referente exterior ao discurso, por si mesmo inacessível: R. Barthes chama este artifício próprio ao discurso historiográfico "o efeito do real", que consiste em esconder sob a ficção de um "realismo" uma maneira, necessariamente interna à linguagem, de propor um sentido. "O discurso historiográfico não segue o real, não fazendo senão significá-lo repetindo sem cessar aconteceu, sem que esta asserção possa jamais ser outra coisa do que o avesso significado de toda a narração histórica (CERTAU, 2006, p. 52).

Vejamos o que Struik (1997), nos diz:

A emergência de uma civilização inteiramente nova era necessária para interromper a ossificação relativa da matemática. A diferente concepção de vida, característica da civilização grega, trouxe finalmente a matemática aos padrões de um novo tipo de ciência (STRUIK, 1997, p. 67).

A escrita de Struik, entendida como prática historiográfica, necessita do substrato das matemáticas egípcias e orientais que lhe sirvam como um corpo, para que nele o conquistador greco-europeu escreva a sua própria história. Desta maneira, "o que assim se disfarça é uma colonização do corpo pelo discurso do poder. É a escrita conquistadora" (CERTAU, 2006, p. 9). Adjetivada como uma mera matemática prática 
na historiografia da matemática, a matemática egípcia tem sido retirada da história ou subalternizada como matemática primitiva ou de ciência pré-lógica.

Esta distorção, visivelmente etnocêntrica, nos convida a romper algumas ideias pré-estabelecidas sobre a África e seu povo. O eurocentrismo tem raízes antigas, provavelmente ligadas ao etnocentrismo greco-romano, cujo símbolo maior é a invenção de um mito chamado "milagre grego". O milagre grego - uma produção discursiva - nos sugere uma ruptura entre uma suposta ciência primitiva e uma suposta ciência verdadeira, entre o raciocínio pré-lógico e a raciocínio lógico, entre a matemática primitiva e a verdadeira matemática. Mas será que a complexidade e amplitude dos acontecimentos históricos ocorrem dessa forma? Com rupturas? Dentro de um esquema binário em oposição a um continuum devir?

Rupturas nunca são neutras ou (des)possuídas de usos e desusos; são estabelecidas num jogo de relações de poder. No jogo eurocêntrico, a Europa tem exercido, e apenas ela, o privilégio de nomear as demais civilizações não europeias, sem por estas ser nomeada. Estamos diante de um jogo de disputas por prestígio cultural e econômico: o milagre grego é um discurso identitário que tenta estabelecer fronteiras culturalmente rígidas e nos conduz ao eurocentrismo científico.

O mito do milagre grego rompe epistemologicamente com os conhecimentos africanos, babilônios e outros, motivados, ainda hoje, pelo colonialismo europeu. Mesmo quando invalidado, a desconstrução deste "milagre" por si só não é capaz de restituir o corpus africano à história da matemática. A mesma "ponte" que conduz o antigo Egito para a história da matemática, também o conduz para o Oriente Médio e, assim, mantém a exclusão do corpus africano. Portanto, o paradigma greco-romano afirma, acima de tudo, que antes dos gregos não havia ciência, filosofia e matemática, ao menos, que pudessem ser consideradas "verdadeiras" do ponto de vista científico.

É assim que uma boa parte das noções que foram popularizadas sobre África, as suas culturas e a sua historicidade, noções que continuam tendo curso em muitas instituições acadêmicas reputadas, não conseguem passar através do crivo de critérios puramente científicos (MOORE, 2004, p. 1).

Para Moore (2004), o paradigma eurocêntrico ou greco-romano é composto por realidades sustentadas por dados supostamente científicos, com base nas crenças de que: 
1) a humanidade surgiu na Eurásia e de lá migrou para o Oriente Médio, África e o resto do mundo;

2) o apogeu das civilizações precursoras na Eurásia foi a chamada civilização grecoromana, considerando-se as demais civilizações, anteriores à greco-romana, tais como Elam, Egito, Babilônia e Índia dravidiana, também de origem euro-asiática. Assim, o Egito faraônico foi "retirado" do continente africano e "enxertado" no Oriente Médio.

Mesmo que os historiadores reconheçam a arbitrariedade imposta em alguns enunciados, a história da matemática é dividida em dois grandes "blocos": a matemática pré-helênica, pré-lógica ou primitiva; e a matemática helênica, lógica ou dedutiva. Evidentemente, há uma diversidade de matrizes de civilizatórias em cada um desses agrupamentos; tanto a fase pré-helênica como a fase helênica são constituídas de enorme variabilidade de culturas matemáticas. Entretanto, sob o jugo greco-europeu, para alguns professores e professoras a matemática está representada como a imagem e semelhança do conquistador:

[...] dá impressão que tudo foi gerado pelos gregos, tanto é que toda a geometria que a gente estuda fala-se apenas de Euclides. Ou seja, foram os gregos que inventaram, foram os gregos que organizaram..., tipo assim..., os outros podem até ter usado e terem criado, mas "nós" [os gregos] somos os chefões, nós que organizamos. É passada essa visão pra gente! (Prof. Teodorinho ${ }^{8}$, entrevista).

Organizando e sistematizando, os gregos, nas palavras do professor Teodorinho, tornaram-se "os chefões" do império matemático, subjugando os demais povos. Esse império matemático provém de práticas que

[...] estão identificadas com a expansão da civilização ocidental, e assim associadas a um sistema de dominação política e econômica que resultou desse processo de expansão. Supostamente, ao falarmos de raízes socioculturais, essas considerações não podem ser esquecidas, e a matemática, como conhecimento de base para a tecnologia e para o modelo organizacional da sociedade moderna, está presente de maneira muito intensa em tudo isso. A matemática e o processo de dominação que prevalece nas relações com o que é hoje o Terceiro Mundo estão intimamente associados. Da mesma maneira que a

\footnotetext{
${ }^{8}$ Professor de matemática da educação básica. Entrevista concedida em 26 de novembro de 2007. Nome fictício.
} 
matemática e os processos de desajuste social interno nos países, inclusive nos países desenvolvidos. Em resumo, a matemática está associada a um processo de dominação e à estrutura de poder desse processo (D'AMBRÓSIO, 1998, p. 14).

Problematizamos, desta forma, a natureza dicotômica na historiografia hegemônica da matemática, de maneira a associar a matemática dos egípcios ao primitivo e, por sua vez, a matemática dos gregos à matemática verdadeira. $\mathrm{O}$ núcleo epistêmico desta narrativa eurocêntrica enuncia representações que dizem muito mais dos sujeitos que os produzem do que dos sujeitos a quem elas estão dirigidas.

Esses dois processos - ter a si próprio como modelo e projetar sobre o outro as mazelas que não se é capaz de assumir, pois maculam o modelo - são processos que, sob certos aspectos, podem ser tidos como absolutamente normais no desenvolvimento das pessoas. O primeiro está associado ao narcisismo, e o segundo à projeção. No entanto, no contexto das relações raciais eles revelam uma faceta mais complexa porque visam justificar, legitimar a idéia de superioridade de um grupo sobre o outro e, conseqüentemente, as desigualdades, a apropriação indébita de bens concretos e simbólicos, e a manutenção de privilégios. [...] Esta forma de construção do Outro a partir de si mesmo é uma forma de paranóia que traz em sua gênese o medo. [...] Desse medo que está na essência do preconceito e da representação que fazemos do outro (BENTO, 2002, p. 31-32).

A subjetivação de uma narrativa anti-africana e antinegra se insere em processos de construção da identidade branco-europeia. Essa subjetivação sugere localizar africanos e afro-brasileiros no lugar de raça ${ }^{9}$, fixando-os na pré-história, favorecendo assim, os interesses dos colonizadores e de seus herdeiros beneficiários.

Face ao exposto, problematizamos que na historiografia hegemônica da matemática, identificamos uma operacionalização de práticas e enunciados que imprimem sentidos e significados de que falar de matemática é igualmente falar de

\footnotetext{
9 'Um 'lugar' de raça é o espaço de visibilidade do outro, enquanto sujeito numa relação, na qual a raça define os termos desta relação. Assim, o lugar do negro é o seu grupo como um todo e do branco é o da sua individualidade. Um negro representa todos os negros. Um branco é uma unidade representativa apenas de si mesmo. Não se trata, portanto, da invisibilidade da cor, mas da intensa visibilidade da cor e de outros traços fenotípicos aliados a estereótipos sociais e morais, para uns, e a neutralidade racial, para outros. As consequências dessa visibilidade para negros são bem conhecidas, mas a da neutralidade do branco é dada como "natural", já que é ele o modelo paradigmático de aparência e de condição humana" (Piza, 2002, p. 72).
} 
matrizes euro-asiáticas. A história da matemática hegemônica é, também, a história da construção de uma identidade histórico-cultural para esta ciência.

De maneira arbitrária, as matemáticas antigas estão agrupadas como ocidentais ou orientais, deslocando a matemática africana produzida no Egito para o contexto oriental. Ressaltamos que todo e qualquer deslocamento provoca algum tipo de apagamento. O apagamento civilizatório africano no desenvolvimento do pensamento matemático é condicionado - além de outros - pelo fato de a África ser/estar narrada numa história eurocentrada como um continente sem civilização. Uma história que ainda hoje produz estereótipos e estigmas negativos contra os africanos e seus descendentes nas diásporas.

Topografia de interesses. Este é, ao nosso ver, o pano de fundo a ser problematizado nos livros de história da matemática e, em especial, nos cursos de licenciatura em matemática, de maneira que possa contribuir para ampliar suas bases epistemológicas e promover justiça histórica. Ao considerar ser importante ao ensino de matemática oportunizar aos alunos e às alunas uma noção de que a "matemática não se desenvolve no vácuo" (Eves, 2004, p. 20), a perspectiva histórico-cultural nesta área de ensino, apresenta-se como algo relevante no campo da educação matemática.

As reflexões trazidas até aqui, nos autorizam a dizer que no processo de inclusão da história e cultura afro-brasileira no currículo escolar, conforme previsto na Lei $\mathrm{n}^{0}$ $10.639 / 03^{10}$, parte dos conhecimentos que utilizamos nos currículos de matemática são conhecimentos africanos desenvolvidos, sobretudo, pela civilização egípcia. Trata-se de compreender que aquilo que a Lei $n^{\circ} 10.639 / 03$ propõe incluir, de certa forma, já permeiam os cotidianos escolares. Neste caso, ao invés mera inclusão, urge a necessidade de identificar a matriz civilizatória africana que habita este conhecimento.

$\mathrm{O}$ ensino de matemática dialogado com uma perspectiva histórica descolonizada, favorecerá a consolidação de relações étnico-raciais que valorizem a diferença, promovendo a alteridade no cotidiano escolar. Ao considerar uma anterioridade africana em face dos gregos, em mais de um milênio em muitos cálculos

\footnotetext{
${ }^{10}$ Esta Lei altera a diretrizes e bases da educação nacional, para incluir no currículo oficial das redes de ensino a obrigatoriedade da temática "História e Cultura Afro-Brasileira".
} 
matemáticos, salta-nos aos olhos a ambiguidade entre o desejo e a rejeição das origens africanas e da sua presença em nossas práticas de ensino de matemática.

Finalizamos com a certeza de que permanece uma questão pouco desvendada na história da matemática: qual a dimensão matemática ainda não revelada que se esconde por trás dos registros que Ahmes copiou e que, hoje, é o trabalho matemático mais antigo que conhecemos? Será, este papiro, analogamente, como pontos de um iceberg, que nos oferecem apenas uma pequena fração do todo?

Se a resposta acima ainda nos está distante, do contrário, cada vez mais nos está próxima a compreensão de que a matriz negro-africana habita - mesmo que de forma silenciada - os currículos praticados no ensino de matemática; igualmente, temos compreensão que a escrita da história está marcada pelo trabalho subjetivo dos historiadores que, "enquanto falam $d a$ história estão situados na história" (Certau, 2006, p. 32). É tempo de modificarmos a narrativa da história e do ensino de matemática!

\section{REFERÊNCIAS BIBLIOGRÁFICAS}

BENTO, Maria Aparecida Silva. Branqueamento e branquitude no Brasil. In: CARONE Iray; BENTO, Maria Aparecida Silva (Org.). Psicologia social do racismo: estudos sobre branquitude e branqueamento no Brasil. Rio de Janeiro: Vozes, 2002. p. 25-58.

BOYER, Carl B. História da matemática. São Paulo: Edgard Blücher, 1994.

BRASIL, Lei de Diretrizes e Bases da Educação Nacional, para incluir no currículo oficial da Rede de Ensino a obrigatoriedade da temática "História e Cultura Afro-Brasileira", LEI No 10.639, DE 9 DE JANEIRO DE 2003. Brasília, 9 de janeiro de 2003; 182o da Independência e 115 o da República. D.O.U. de 10.1.2003

CERTAU, Michel de. A escrita da história. Rio de Janeiro: Forense Universitária, 2006.

D’AMBRÓSIO, Ubiratan. Etnomatemática. São Paulo: Ática, 1998.

DIOP, Cheikh. Anta. A origem dos egípcios. In: MOKHTAR, G. (coord.). História Geral da África: a África antiga. São Paulo: Ática/Unesco, 1983. v. 2, p. 39-70.

EVES, Howard. Introdução à história da matemática. Campinas: Editora da Unicamp, 2004.

FONTES, Hélio Carvalho d'Oliveira. No passado da matemática. Rio de Janeiro: FGV, 1969.

FORDE, Gustavo Henrique Araújo. O QUE PROFESSORES CALAM E DIZEM SOBRE A PRESENÇA AFRICANA NO ENSINO DE MATEMÁTICA?. Revista da Associação 
Brasileira de Pesquisadores/as Negros/as (ABPN), [S.1.], v. 9, n. 22, p. 251-272, jul. 2017. ISSN 2177-2770. Disponível

em: $<$ http://abpnrevista.org.br/revista/index.php/revistaabpn1/article/view/407>. Acesso em: 13 set. 2019.

FORDE, Gustavo Henrique Araújo. A presença africana no ensino de matemática: análises dialogadas entre história, etnocentrismo e educação. Dissertação (Mestrado em Educação) Programa de Pós-Graduação em Educação, Universidade Federal do Espírito Santo - UFES, Vitória, 2008.

GABAGLIA, Raja. Calculo pratico, origem e primitivo desenvolvimento das operações: origem das formas artificiaes do numero. In: Revista da Escola Polytechnica. Rio de Janeiro: Imprensa Americana, 1897a. p. 137-149.

GABAGLIA, Raja. O mais antigo documento mathematico conhecido: algebra do papyro Rhind. In: Revista da Escola Polytechnica. Rio de Janeiro: Imprensa Americana, 1897b. p. 217237.

GABAGLIA, Raja. O mais antigo documento mathematico conhecido: historico. In: Revista da Escola Polytechnica. Rio de Janeiro: Imprensa Americana, 1897c. p. 268-308.

HUYLEBROUCK, Dirk. África: berço da matemática. Scientific American Brasil, Etnomatemática, São Paulo, n. 11, p. 42-47, jul. 2006. Edição Especial.

MINISTÉRIO DA EDUCAÇÃO E CULTURA. Diretrizes curriculares nacionais para a educação das relações étnico-raciais e para o ensino de história e cultura afro-brasileira e africana. Brasília: MEC, 2004.

MOORE, Carlos. A África e o mundo: introdução à obra e ao pensamento de Cheik Anta Diop. In: SEMINÁRIO DE INTRODUÇÃO À OBRA E AO PENSAMENTO DO PROF. CHEIK ANTA DIOP, 2004, São Paulo: Casa das Áfricas, 2004. (mimeo)

NASCIMENTO, Abdias do. O quilombismo. Rio de Janeiro: Vozes, 1980.

NASCIMENTO, Elisa Larkin (Org). Sankofa: matrizes africanas da cultura brasileira. Rio de Janeiro: EdUERJ, 1996.

PIZA, Edith. Porta de vidro: entrada para a branquitude. In: CARONE Iray; BENTO, Maria Aparecida Silva (Org.). Psicologia social do racismo: estudos sobre branquitude e branqueamento no Brasil. Rio de Janeiro: Vozes, 2002. p. 59-90.

STRUIK, Dirk. J. História concisa das matemáticas. Lisboa, PT: Gradiva, 1997.

Recebido em: 30/09/2019

Aceito em: 30/11/2019 